\title{
USUCAPIÃO POR ABANDONO DE LAR: LEI № 12.424 DE 16 DE JUNHO DE 2011
}

\section{Edwirges Elaine Rodrigues Maria Amália de Figueiredo Pereira Alvarenga}

ISSUE DOI: $10.21207 / 1983.4225 .251$

\section{RESUMO}

O presente artigo aborda a mais nova modalidade de usucapião, que surgiu com o advento da Lei n. 12.424, de 16 de junho de 2011, a qual acrescentou o art. 1.240-A ao Código Civil. Tal modalidade de usucapião, que acontece entre ex-cônjuges ou ex-companheiros, será denominada neste trabalho como usucapião por abandono de lar, tendo em vista que essa expressão está presente no texto da lei, sendo também o objeto de maior discussão entre os operadores do Direito. Por ter aspectos que dizem respeito ao Direito de Família, essa usucapião não deixa de causar reflexos àquele Direito abordado, também, por esse artigo.

Palavras-chave: Usucapião. Ex-cônjuge. Ex-companheiro. Abandono de lar. Abandono do imóvel.

\section{INTRODUÇÃO}

Trata-se da mais nova espécie de usucapião, que, também é denominada pela doutrina de "usucapião pró-família", "usucapião familiar" ou "usucapião entre cônjuges". Entretanto, entende-se ser mais bem defi- 
nida por "usucapião por abandono de lar", ao passo que poderão usufruir desse benefício apenas os cônjuges/companheiros, e não qualquer familiar. Além do mais, insta diferenciar essa modalidade daquela categoria de usucapião especial rural, prevista no art. 191 da Constituição Federal, que também tem conotação familiar.

A usucapião por abandono de lar foi inserida no ordenamento jurídico brasileiro através da Lei $n^{\circ}$. 12.424, de 16 de junho de 2011, a qual, ao tutelar questões relativas ao plano Minha Casa Minha Vida, do Governo Federal, acrescentou a alínea A ao artigo 1.240 do Código Civil, que passou a ter a seguinte disposição:

Art. 1.240-A. Aquele que exercer, por 2 (dois) anos, ininterruptamente e sem oposição, posse direta, com exclusividade, sobre imóvel urbano de até $250 \mathrm{~m}^{2}$ (duzentos e cinquenta metros quadrados), cuja propriedade divida com ex-cônjuge ou excompanheiro que abandonou o lar, utilizando-o para sua moradia ou de sua família, adquirir-lhe-á o domínio integral, desde que não seja proprietário de outro imóvel urbano ou rural.

$\S 1^{\circ}$. O direito previsto no caput não será reconhecido ao mesmo possuidor mais de uma vez.

Para ser configurada a usucapião por abandono de lar, devem ser observados vários quesitos, sendo que alguns deles se assemelham aos pressupostos exigidos nas outras modalidades de usucapião, enquanto outros requisitos são específicos dessa nova modalidade de prescrição aquisitiva.

Desta forma, os pressupostos indispensáveis para a propositura da ação de usucapião por abandono de lar serão abordados a seguir. 
Esclarece a norma que tem legitimação ativa para propositura da usucapião por abandono de lar aquele ex-cônjuge ou ex-companheiro, inclusive homoafetivo ${ }^{1}$, que permaneceu no lar após a saída do outro.

Não obstante, para que o ex-cônjuge ou ex-companheiro obtenha a legitimidade, ele deve ser coproprietário do bem usucapiendo, além de utilizar o imóvel abandonado para fins de moradia própria ou de sua família, por dois anos, atingindo, assim, a função social da propriedade, que tem por objetivo primordial garantir o direito à moradia àquele que exerce a posse de determinada propriedade.

Nesse sentido, preleciona Caio Mário da Silva Pereira:

A consagração normativa do instituto apoia-se em pressupostos específicos, comprovando sua aplicação restrita. A começar pela necessidade de que o parceiro abandonado divida a titularidade do imóvel com o abandonador e continue a residir no bem após o evento - a lei diz "utilizando-o para sua moradia ou de sua família". Vale dizer, o cônjuge ou companheiro permanece a residir no imóvel do qual detém uma parcela da propriedade e vai, com o transcurso do biênio legal, adquirir a propriedade da fração pertencente ao outro, integralizando o domínio em seu nome ${ }^{2}$.

Entretanto, o requisito "utilizando-o para sua moradia ou de sua família" não pode ser aplicado em seu sentido literal, pois se exige a posse personalíssima e exclusiva do ex-cônjuge usucapiente.

Assim, não se pode permitir que tal cônjuge requeira essa modalidade de usucapião, enquanto apenas sua família resida no imóvel.

Quanto ao legitimado passivo, trata-se do cônjuge abandonador do imóvel, de cujo bem é coproprietário. Mormente o cônjuge que toma a iniciativa de pôr fim ao relacionamento tende a abandonar o lar, deixando para trás o domínio do imóvel comum.

\footnotetext{
${ }^{1}$ Enunciado 500 da V Jornada de Direito Civil: "A modalidade de usucapião prevista no art. 1.240-A do Código Civil pressupõe a propriedade comum do casal e compreende todas as formas de família ou entidades familiares, inclusive homoafetivas".

2 PEREIRA, Caio Mário da Silva. Instituições de direito civil. 21. ed. Rio de Janeiro: Forense, 2012. p. 132.
} 
Além do mais, a nomenclatura "abandono do lar" significa o fato daquele que deixou de praticar atos que são inerentes ao proprietário, tais como uso, gozo, disposição ou reivindicação. Assim, abandono, no caso em tela, quer dizer a falta do exercício dos atos possessórios.

Em consequência do abandono, o cônjuge que fica na propriedade passa a exercer a posse personalíssima com exclusividade sobre o imóvel. Passado o lapso temporal de dois anos, esse cônjuge adquire a propriedade do imóvel, podendo regularizá-la através da ação de usucapião por abandono de lar.

\section{DO IMÓVEL A SER USUCAPIDO}

Apenas o imóvel urbano poderá ser objeto da usucapião por abandono de lar. É a moradia e não o trabalho que se privilegia. Por isso, o art. 1.240-A surge em sede de regulamentação do programa do Governo Federal "Minha casa, Minha vida".

Destarte, o imóvel rural foi excluído dessa modalidade de usucapião. Contudo, muito se critica a respeito dessa exclusão, pois a localização do domicílio de uma pessoa não é critério justificativo para tratamento diferenciado, caracterizando, assim, ofensa ao princípio da isonomia.

Em defesa da aplicação da legislação também às famílias que vivem na área rural, alega Luciana Santos Silva:

Nesse sentido, os efeitos do abandono são os mesmos, independente da localização do imóvel em que ficou residindo o abandonado. Quiçá não sejam mais gravosos na zona rural, na qual as relações sociais mais próximas favorecem que a pecha de abandonado passe a integrar de forma pejorativa a identidade social do que permaneceu no imóvel. Além disso, no Brasil, os índices de baixa escolaridade e alta pobreza são mais acentuados na 
zona rural, gerando entraves ao acesso à Justiça e a efetivação de direitos ${ }^{3}$.

Ainda, o imóvel deve ser de propriedade do casal que surge com o casamento ou com a união estável, seja ela hétero ou homossexual.

No mais, segundo o art. 1.240-A, o imóvel deve possuir metragem de até $250 \mathrm{~m}^{2}$ (duzentos e cinquenta metros quadrados). Porém, imóveis com essa dimensão, dependendo da localização, podem representar valor elevado, podendo caracterizar o empobrecimento do ex-cônjuge abandonador e consequente enriquecimento ilícito do ex-cônjuge usucapiente.

Muitas críticas foram feitas nesse sentido, sendo uma delas a de Priscila Maria Pereira Corrêa da Fonseca:

Por fim, será que antes de editar a nova lei, refletiu o legislador a circunstância de que um imóvel de 250 $\mathrm{m}^{2}$ pode representar um bem de altíssimo valor econômico - há apartamentos de tais dimensões cujo valor ultrapassa a casa dos três milhões de reais - e que a perda, ainda que parcial, desse montante pode empobrecer sobremaneira aquele que 'abandonou' o lar e enriquecer injustificadamente o outro que nele ficou albergado ${ }^{4}$

Assim, o cônjuge que adquirir propriedade nos moldes da citação acima, estará se beneficiando abusivamente; em contrapartida, o que perde sua meação sofre do empobrecimento desproporcional.

Desse modo, deverá o Magistrado sobrepor-se criteriosamente para evitar situações realmente injustas.

3 SILVA, Luciana Santos. Uma afronta à Carta Constitucional: usucapião pró-família. Revista Síntese Direito de Família. v. 14. n. 71, pp. 32-36. São Paulo, abr. e maio. 2012. p. 34.

${ }^{4}$ FONSECA, Priscila Maria Pereira Corrêa da. Considerações sobre o art. 1.240-A: atos normativos e novidades legislativas. Revista Brasileira de Direito de Família e Sucessões. Porto Alegre: Magister; Belo Horizonte: IBDFam, a. 13, n. 23. ago. e set. 2011. p. 120. 


\section{DA POSSE}

A posse exigida pelo art. 1.240-A do Código Civil requer a observância de elementos especiais: “(...) aquele que exercer, por 2 (dois) anos, ininterruptamente e sem oposição, posse direta, com exclusividade (...)."

Desse modo, é exigido que o ex-cônjuge ou ex-companheiro que permanece no imóvel tenha a posse direta, ou seja, deve ter o imóvel em seu poder de forma imediata, cabendo somente a esse o direito de usucapir o bem, não transmitindo esse direito a terceiros. Daí o significado da expressão "com exclusividade", pois a posse é personalíssima.

Entretanto, não basta que o ex-cônjuge ou ex-companheiro seja o possuidor para se beneficiar da usucapião por abandono de lar. Conforme a lei estabelece, o imóvel a ser usucapido deve ser de propriedade de ambos os cônjuges ou companheiros. Dessa forma, o cônjuge ou companheiro usucapiente deve ser possuidor e coproprietário do imóvel.

No mais, a posse deve ser de, no mínimo, dois anos contínuos, sem interrupção e, principalmente, sem oposição.

Assim, o ex-cônjuge ou ex-companheiro deve deixar de apresentar qualquer manifestação relativa a seu interesse sobre a propriedade durante dois anos, para que se caracterize a falta de oposição.

Caso o ex-cônjuge ou ex-companheiro que abandonou o lar tenha reivindicado a sua posse judicialmente ou extrajudicialmente, não ficará caracterizada a posse ad usucapionem, então, a ação de usucapião estará prejudicada.

\section{DA PROPRIEDADE EM RELAÇÃO AO REGIME DA COMUNHÃO DE BENS}

Como já dito, a usucapião por abandono de lar deve recair sobre imóvel comum do casal.

Assim, o imóvel pode ter sido adquirido na constância do regime de comunhão total de bens, em que os bens particulares e os adquiridos durante o casamento se comunicam, sendo passíveis da nova usucapião. 
Também poderá ser usucapido, o imóvel adquirido durante o matrimônio regido pela separação parcial de bens, haja vista tratar-se de regime de separação quanto ao passado e de comunhão quanto ao futuro, aplicando-se esse dispositivo à união estável, em decorrência da semelhança dos regimes.

Quanto ao regime de separação convencional de bens, no qual os nubentes optam pela incomunicabilidade total de bens, o imóvel poderá ser passível da usucapião por abandono de lar, caso o imóvel tenha sido adquirido por ambos os cônjuges, pois, dessa forma, esse bem se comunicará, segundo a Súmula no .377 do STF: "No regime de separação legal de bens, comunicam-se os adquiridos na constância do casamento".

Nesse caso, inexiste a comunhão; no entanto, existe o condomínio do bem e, por essa razão, enquadra-se na referida modalidade de usucapião.

Segundo Maria Aglaé Tedesco Vilardo, mesmo que o bem tenha sido adquirido por apenas um dos cônjuges e o regime de bens seja a separação total, sendo esse bem utilizado como moradia do casal, deverá incidir o prazo da usucapião por abandono de $1 \mathrm{r}^{5}$.

Todavia, a doutrina majoritária entende que, havendo a aquisição do imóvel somente por um dos cônjuges, não há como suscitar a usucapião, pois a lei exige a copropriedade do bem.

\section{$5 \quad$ DO LAPSO TEMPORAL}

O prazo exigido, na usucapião por abandono de lar, para que o possuidor transforme-se em proprietário, é de apenas 2 (dois) anos. Esse é o prazo mais curto dentre as demais modalidades de usucapião, inclusive de bens móveis, em que se requer o prazo de 3 (três) anos.

A brusca redução do lapso temporal causou grande espanto entre os doutrinadores e operadores do Direito, que consideram o prazo bastante exíguo em meio às dificuldades inerentes de uma separação e suas consequências com relação à questão financeira e filhos.

Esse é o entendimento de José Fernando Simão:

5 VILARDO. Maria Aglaé Tedesco. Usucapião especial e abandono de lar: usucapião entre ex-casal. Revista Brasileira de Direito de Família e Sucessões. Porto Alegre: Magister; Belo Horizonte: IBDFam, n. 27. abr. e maio 2012. p. 54. 
A lei presume, no meu sentir de maneira equivocada, que, quando o imóvel é familiar, deve o prejudicado, pela posse exclusiva do outro cônjuge ou companheiro, tomar medidas mais rápidas, esquecendo-se que o fim da conjugalidade envolve questões emocionais e afetivas que impedem, muitas vezes, rápida tomada de decisão. É o luto pelo fim do relacionamento. ${ }^{6}$

Contrariamente à citação acima, Flávio Tartuce compreende que "a tendência pós-moderna é justamente a de redução dos prazos legais, eis que o mundo contemporâneo exige e possibilita a tomada de decisões com maior rapidez"7.

Do mesmo modo, também entende Caio Mário da Silva Pereira:

$\mathrm{Na}$ espécie, o prazo para conversão da posse em propriedade reduz-se a apenas dois anos, proporcionando a tutela mais célere dos direitos do cônjuge ou companheiro abandonado pelo outro, em beneficio da preservação dos interesses existenciais de todas as pessoas que integram a entidade familiar. $^{8}$

Portanto, ao reduzir o prazo para dois anos de posse exclusiva após a separação de fato, a regra tem por finalidade privilegiar a proteção da segurança jurídica, essencial a toda usucapião9 .

\section{COMPETÊNCIA JUDICIÁRIA}

\footnotetext{
${ }^{6}$ SIMÃO, José Fernando. Usucapião familiar: problema ou solução? Artigo disponível em: <http://www.professorsimao.com.br/artigos_simao_cf0711.html>. Acesso em 27 de maio de 2013.

7 TARTUCE, Flávio. A usucapião especial urbana por abandono do lar conjugal. Revista Síntese Direito de Família. v. 14. n. 71, pp. 16-18. São Paulo, abr. e maio 2012. p. 17.

${ }^{8}$ PEREIRA, Caio Mário da Silva, op. cit.. p. 132.

${ }^{9}$ ABULQUERQUE JÚNIOR, Roberto Paulino; GOUVEIA FILHO, Roberto P. Campos. Primeiras anotações sobre os pressupostos e a processualização da usucapião familiar. Revista de Processo. a. 36. v. 199. set./2011. p. 371.
} 
Haja vista que o instituto da usucapião por abandono de lar só pode ser aplicado ante o reconhecimento da relação familiar, no casamento ou união estável, ao passo que essa última deve ser especificamente comprovada, entende-se que a competência para julgamento dessas ações é das Varas de Família.

Além do mais, deve-se fazer prova da separação de fato, tendo em vista que a lei se refere a ex-cônjuge ou ex-companheiro.

Logo, a aquisição da propriedade por esse instituto também afetará diretamente a partilha, porque afasta dela o bem cuja meação foi usucapida.

Dessa forma, os negócios jurídicos entre familiares necessitam de um tratamento específico não comum às Varas Cíveis, pois são repercutidos de forte emoção.

Em consonância, seguem as orientações da Juíza de Direito Titular da $15^{\text {a }}$ Vara de Família da capital do Rio de Janeiro, Maria Aglaé:

A solução mais indicada deverá ser aquela existente nas Varas de Família. É por isso que temos a especialização da justiça. O foco do juízo de família tem algumas peculiaridades diferentes do juízo cível. A partilha do imóvel comum, a doação da parte de um dos cônjuges ou de ambos para os filhos, o uso da totalidade do imóvel por determinado período até que os filhos cresçam, enfim, diversas são as soluções que sempre se apresentaram nas Varas de Família ${ }^{10}$.

Entretanto, como não está previsto na lei qual é o juízo competente, acredita-se que haverá enfrentamentos até que a jurisprudência se pacifique sobre a aplicação do novel instituto.

\section{VIGÊNCIA DA LEI}

\footnotetext{
${ }^{10}$ VILARDO. Maria Aglaé Tedesco. Usucapião especial e abandono de lar - usucapião entre ex-casal. Revista Brasileira de Direito de Família e Sucessões. Porto Alegre: Magister; Belo Horizonte: IBDFam, n. 27. abr. e maio 2012. p. 56-57.
} 
Em relação à aplicabilidade da usucapião por abandono de lar, como a norma é omissa quanto à sua vigência, compreende-se que as ações dessa espécie de usucapião poderão ser propostas, apenas, passados 2 (dois) anos da publicação da lei.

Esse entendimento se dá em defesa do princípio da segurança jurídica, que tem por finalidade não gerar surpresas a quem se destina.

Entretanto, no mesmo ano em que a lei entrou em vigência, sem atender ao prazo de dois anos após sua publicação, o juiz Geraldo Claret de Arantes, em cooperação na $3^{\mathrm{a}}$ Vara de Família de Belo Horizonte, concedeu o benefício da nova modalidade de usucapião a uma mulher divorciada, dando-lhe direito ao domínio integral de um imóvel que possuía em copropriedade com seu ex-marido, que se encontrava em local incerto e não sabido. A decisão foi proferida, tendo em vista que, no pedido liminar à Justiça, a mulher comprovou ser portadora de doença grave, necessitando imediatamente do pleno domínio da casa onde vive para resolver questões pendentes. A não localização do ex-marido, comprovada nos autos, impedia qualquer negociação que envolvesse o imóvel.

\section{DO ABANDONO DO LAR E A DISCUSSÃO QUANTO À POSSÍVEL INCONSTITUCIONALIDADE DA LEI}

Dentre as inovações trazidas pelo artigo 1.240-A, a mais discutida é sobre o abandono do lar, expressão que deu nome à nova modalidade de usucapião.

Em todas as demais espécies de usucapião existentes, o principal pressuposto para adquirir a propriedade do imóvel é o ânimo de dono, ou seja, a intenção de ter a coisa como própria. Porém, o mesmo não se dá na usucapião em tela, pois a indagação é a respeito do abandono do lar por parte de um dos cônjuges.

Tamanha é a discussão a respeito dessa expressão, que surgiram duas correntes que a interpretam de formas distintas.

A primeira corrente, liderada por Maria Berenice Dias e José Fernando Simão, entende que o abandono de lar presente no art. 1.240-A do Código Civil é a mesma expressão abandono do lar mencionada no art. 1.573, inciso IV, do Código Civil, que, ao tratar da separação judicial, diz que o abandono voluntário do lar conjugal, durante um ano contínuo, pode caracterizar a impossibilidade da comunhão de vida. 
Entretanto, a jurisprudência, há muito tempo, percebe que a atitude de deixar o lar conjugal não representa culpa na separação. Essa sanção também deixou de ser aplicada com o advento da Emenda Constitucional n. 66/2010, que alterou o art. 226, § 6 $6^{\circ}$ da Constituição Federal, passando a admitir o divórcio direto ${ }^{11}$.

Assim, a culpa da separação não é mais indagada em juízo; o divórcio pode ser requerido e decretado sem qualquer questionamento: basta ao menos uma das partes ingressar com a ação.

Portanto, os motivos pelos quais se requer o divórcio, sejam eles graves ou não, em nada interferem nos direitos e deveres correlatos ao casamento ou união ${ }^{12}$.

Dessa feita, os juristas defensores dessa corrente entendem haver um retrocesso da norma, pois, como dito acima, a expressão "abandono de lar", que deixou de ser utilizada pela legislação em vigor, volta nessa nova modalidade de usucapião.

Desse modo, esse dispositivo seria inconstitucional, tendo em vista a promoção de um verdadeiro retrocesso jurídico, afrontando o princípio constitucional de vedação ao retrocesso. Tal princípio sustenta que a aplicação prática da norma se dê de forma atual, contextualizada e, sobretudo, sistematizada ${ }^{13}$.

Segundo essa corrente, a volta da discussão a respeito da culpa pela separação de fato seria, sem dúvida, um retrocesso jurídico, já que essa questão já foi superada pela jurisprudência.

Já a segunda corrente defende que a expressão abandono de lar do art. 1.240-A nada tem a ver com a já inaplicada expressão presente na separação judicial.

Entre seus defensores está Ricardo Henrique Pereira Amorim, que interpreta o abandono de lar da seguinte maneira:

Colimando a pretensão social ao expurgo da culpa do direito de família e a mens legis voltada à Justiça

\footnotetext{
11 VILARDO. Maria Aglaé Tedesco, op. cit., p. 49.

12 Idem. p. 50.

${ }^{13}$ FREITAS, Douglas Phillips. Usucapião e direito de família: comentários ao art. 1.240A do código civil. Revista Síntese Direito de Família. v. 14. n. 71, pp. 9-15. São Paulo, abr./maio. 2012. p. 11.
} 
Social, temos que o abandono de lar deve ser analisado sobre a vertente da função social da posse e não quanto à moralidade da culpa pela dissolução do vínculo conjugal. Ou seja, não é de se analisar se o abandono de fato caracterizou culpa, ou se, ao evadir-se, foi legítimo ou até mesmo urgente. Buscará apenas qual dos dois permaneceu dando destinação residencial ao imóvel e pronto, independente da legitimidade da posse e do abandono ${ }^{14}$.

Visto que a finalidade da usucapião é tutelar a segurança das relações que se prolongam no tempo, ela não é sanção àquele que perde a propriedade.

Contudo, percebe-se que o abandono deve ser considerado como a inércia de se praticar os atos de proprietário e possuidor do imóvel, ou seja, não pode usar ou gozar do bem. De tal modo, abandono, no caso em tela, quer dizer a certeza da falta do exercício de atos possessórios.

Também é defensora desse ponto de vista Helena de Azevedo Orselli:

A infeliz redação dada ao art. 1.240-A do Código Civil aponta "o abandono do lar" como um dos requisitos dessa usucapião. Todavia, o artigo em questão é norma de direito real, e não norma de Direito de Família. Em conformidade com o já exposto, a expressão abandono do lar sugere antiga discussão que se tratava, nas separações judiciais litigiosas, para saber qual dos cônjuges era o culpado pelo fim do casamento. A caracterização da usucapião nada tem a ver com a culpabilidade ou não pelo fim do casamento, com o abandono do lar ter sido voluntário ou necessário; enfim, a usucapião, como instituto de direito real, tem como um de seus

14 AMORIM, Ricardo Henriques Pereira. Primeiras Impressões Sobre a Usucapião Especial Urbana Familiar e suas Implicações no Direito de Família. Disponível em: <http://www.ibdfam.org.br/artigos/detalhe/760>. Acesso em 10 de jun. de 2013. 
requisitos o "abandono do bem a ser usucapido", e não o abandono do lar conjugal ou da família ${ }^{15}$.

Entende-se que a segunda corrente é a mais correta, pois o abandono referido nessa usucapião deve ser relacionado ao imóvel, e não o abandono da família.

Trata-se de direito real, ao passo que o referido abandono está entre os modos da perda da propriedade, presente no art. 1.275, inciso III, do Código Civil.

No abandono, o proprietário deixa de exercer qualquer poder em relação ao bem, com a intenção de não mais tê-lo para si, sem expressa manifestação da vontade ${ }^{16}$.

Em análise a essa segunda corrente, consegue-se visualizar a importância da criação dessa usucapião, haja vista ser muito comum que um dos cônjuges, normalmente o homem, deixe o imóvel após o rompimento do casamento ou união estável, mudando-se para local incerto, sem ao menos deixar notícias, deixando o cônjuge possuidor do imóvel de mãos atadas, pois nada se pode fazer com o bem, sem autorização do cônjuge abandonador.

Assim sendo, a situação acima demonstrada seria perfeitamente resolvida através da usucapião por abandono de lar, pois, passados dois anos do abandono do imóvel, o direito de propriedade integral do bem, por parte do cônjuge possuidor, já estaria adquirido pela prescrição aquisitiva, devendo apenas ser formalizada a usucapião para posterior registro da propriedade.

\section{$9 \quad$ OS REFLEXOS DO INSTITUTO NO DIREITO DE FAMÍLIA}

\footnotetext{
15 ORSELLI, Helena de Azeredo. Análise crítica da usucapião por abandono. Revista Síntese Direito de Família. v. 13. n. 69. pp. 129-138. dez./jan. 2012. p. 135.

16 MARTINS, Fernanda da Silva. A usucapião especial urbana por abandono do lar conjugal: a volta da culpa? Artigo disponível em: <http://www3.pucrs.br/pucrs/files/uni/poa/direito/graduacao/tcc/tcc2/trabalhos2012_1/fer nanda_martins.pdf $>$. Acesso em 19 de maio de 2013.
} 
Embora o instituto da usucapião pertença aos Direitos Reais, por tratar-se da prescrição aquisitiva de um bem, essa nova usucapião abordada neste trabalho não concerne unicamente ao Direito das Coisas.

Muitas são as características que fazem com que a usucapião presente no art. 1.240-A do Código Civil, constante do Livro do Direito das Coisas, também faça parte do Direito de Família e seja por ele regulamentada.

Iniciando-se pelos legitimados da ação de usucapião: segundo a lei, devem ser cônjuges ou companheiros e necessitam estar separados de fato. Igualmente, tanto o instituto do casamento, quanto o da união estável, além da separação, são tratados pelo Direito de Família.

No mais, exige-se a copropriedade do imóvel. Desse modo, para que essa copropriedade seja estabelecida, é necessário analisar o regime de bens adotado pelos cônjuges, estando presente mais uma vez o Direito de Família.

Apenas não se pode concordar que o abandono de lar mencionado nessa usucapião seja considerado como aquele presente no Direito de Família ao falar da separação, haja vista que se faz maior sentido apreciá-lo como abandono do imóvel, objeto da usucapião, conforme mencionado no capítulo anterior.

Destarte, comprovada a relação do Direito de Família com a usucapião presente no art. 1.240-A do Código Civil, tornam-se indiscutíveis os reflexos que o instituto pertencente aos direitos das coisas causa em face das famílias.

Percebe-se que um dos possíveis danos causados ao Direito de Família pela usucapião por abandono de lar ocorre em decorrência da possibilidade da decadência da instituição familiar, uma vez que põe fim à possibilidade de restauração do relacionamento após a pressão do legislador de se tomar uma rápida decisão com a finalidade de regularizar a situação conjugal.

Segundo Mônica Guazelli:

Com efeito, o legislador criou uma norma que acaba por impor a necessidade de tomada de atitude para formalização da ruptura do casal, quando, quiçá, o mais adequado fosse resguardar aos companheiros ou cônjuges a possibilidade de aguardar que essa ruptura familiar se acomodasse e se estabilizasse 
naturalmente no mundo dos fatos para, apenas posteriormente, ser formalizado o rompimento no universo jurídico, e se fosse o caso ${ }^{17}$.

O vínculo sentimental existente ao longo de uma separação é muito forte. Dessa forma, a lei desobedece ao ciclo natural da separação, evitando muitas vezes, que a reconciliação prevaleça, pois, ocorrida a ruptura da relação, aquele cônjuge que pretende deixar o imóvel deve tomar as medidas cabíveis, de modo a não dar oportunidade à aplicação da usucapião por abandono de lar.

O prazo de 2 (dois) anos estipulado pelo legislador é considerado muito curto por inúmeros doutrinadores, visto que uma separação tem suas próprias dificuldades, que não são poucas, com reflexos em relação aos filhos e às questões financeiras. ${ }^{18}$

\section{DAS FORMAS DE SE EVITAR A PERDA DA PROPRIEDADE}

O domínio absoluto do imóvel não será conferido se houver, por parte do que deixou a antiga morada, durante os dois anos, oposição ao exercício da posse exclusiva por parte daquele que nele remanesceu.

Destarte, caso o ex-cônjuge ou ex-companheiro que deixou o imóvel manifeste, durante o biênio mencionado pela lei, por qualquer meio ou modo, a sua insatisfação em relação ao uso do bem pelo cônjuge que lá permaneceu, a propriedade exclusiva a esse não pertence mais.

No entanto, também será possível causador de discórdia a interpretação da "falta de oposição" por parte do cônjuge que saiu do imóvel. Para Priscila da Fonseca, configura-se oposição a manifestação verbal ou por escrito e comprovada, por meio de testemunhas, documentos ou outro meio de prova. ${ }^{19}$

17 GUAZZELLI, Mônica. Usucapião por abandono do lar conjugal: repercussões no direito de família. Revista Brasileira de Direito de Família e Sucessões. Porto Alegre: Magister; Belo Horizonte: IBDFam, v. 28. jun./jul. 2012. p. 99.

18 VILARDO. Maria Aglaé Tedesco, op. cit., p. 52.

${ }^{19}$ FONSECA, Priscila Maria Pereira Corrêa da. Considerações sobre o art. 1.240- A. Atos normativos e novidades legislativas. Revista Brasileira de Direito de Família e Sucessões. Porto Alegre: Magister; Belo Horizonte: IBDFam, v. 23. ago/set. 2011. p. 121. 
Aos olhos de Flávio Tartuce, a notificação extrajudicial anual do ex-consorte que resida no imóvel, demonstrando sua vontade em relação ao bem, afasta o cômputo do prazo ${ }^{20}$.

Contudo, esse não é o entendimento de Douglas Phillips Freitas. Para ele, não basta que o cônjuge temeroso em perder sua meação promova notificações ou realize boletins de ocorrência, mas, para que seja desnaturada a posse ininterrupta e sem oposição, o cônjuge que deixou o imóvel deve buscar medida efetiva a fim de assegurar seus direitos sobre o bem, devendo ser proposta ação de divórcio, dissolução de união estável, se for o caso, arbitramento de aluguel, concessão de usufruto ou fixação de comodato $^{21}$.

Em consonância com esse último posicionamento, Carlos Eduardo de Castro Palermo também entende haver necessidade da utilização de procedimentos específicos, tais como divórcio, separação, partilha de bem comum, separação de corpos, além do uso da Lei Maria da Penha (Lei n. 11.340/2006), em que há decisão judicial do afastamento do esposo ou companheiro do lar, como medida de assegurar a integridade física da vítima ${ }^{22}$.

Também descaracterizará o abandono do imóvel, caso o excônjuge ou ex-companheiro proprietário demonstrar interesse pelo imóvel através da contribuição para manutenção e conservação do bem, contribuição para o recolhimento dos tributos relacionados ao imóvel, mesmo que o bem seja residência apenas do outro cônjuge.

Assim, ao decidirem os cônjuges pelo fim do casamento ou união estável, devem eles, consensualmente, tomar uma das medidas acima mencionadas, a fim de se regularizar a situação do imóvel. Caso o fim do relacionamento conjugal seja litigioso, cabe ao cônjuge que pretende deixar o imóvel precaver-se antes de completados os dois anos.

\section{CONCLUSÃO}

\footnotetext{
${ }^{20}$ TARTUCE, Flávio, op. cit.. p. 17.

${ }^{21}$ FREITAS, Douglas Phillips, op. cit.. p. 14.

22 PALERMO, Carlos Eduardo de Castro. A nova usucapião especial por abandono de lar e a função social da propriedade. Revista Síntese Direito de Família. v. 14. n. 71, pp. 1931, São Paulo, abr./maio. 2012. p. 27.
} 
O novel instituto da usucapião, desde o seu surgimento, vem sofrendo inúmeras críticas entre os operadores do Direito. Muitos alegam se deparar com mais problemas que soluções, e caracterizam essa usucapião como desnecessária.

$\mathrm{Na}$ realidade, o que ocorre são interpretações da lei de forma variada entre os juristas, fazendo com que, para alguns, a nova usucapião seja uma conquista, enquanto, para outros, seja uma perda de tempo, ou melhor, um retrocesso.

A possível inconstitucionalidade da norma também foi apontada em relação à expressão "abandono de lar" usada pela lei, bem como em relação à forma de inserção da nova usucapião no ordenamento jurídico.

Como dito ao longo deste artigo, além da redução do lapso temporal, condenado por muitos juristas por ser muito exíguo, a principal discussão é a respeito da expressão "abandono de lar", formando-se duas correntes que se opõem.

A primeira corrente defende a inconstitucionalidade da norma por interpretar a volta da culpa no término do relacionamento conjugal, já extinto pela Emenda Constitucional n. 66/10, que alterou o art. 226, $\S 6^{\circ}$, da Constituição Federal, dando possibilidade ao divórcio direto, sem necessidade de justificativa por parte dos cônjuges.

Enquanto isso, a segunda corrente interpreta a expressão como sendo abandono do imóvel, ou seja, inércia dos poderes inerentes à propriedade.

Entretanto, entende-se que a segunda corrente é a mais correta, tendo em vista que a usucapião trata-se de Direito Real e não de Direito de Família, apesar de provocar reflexos nesse último Direito.

De tal modo, resolvida essa questão da possível inconstitucionalidade do instituto, alegada pelos doutrinadores, foram analisados outros aspectos constitucionais da usucapião.

Nota-se que os pressupostos para a aplicação da usucapião por abandono de lar têm conotação familiar, haja vista o requisito da separação de fato, devendo-se fazer prova dessa, tanto no casamento quanto na união estável, além da análise do regime de bens adotado na constituição do casamento ou união estável.

Assim, é inevitável que o instituto pertencente aos Direitos das Coisas não reflita no Direito de Família, trazendo alguns pontos negativos para o Direito Familiar. 
O vínculo sentimental existente ao longo de uma separação é muito forte. Dessa forma, ao estabelecer o prazo de dois anos para o direito de aquisição da propriedade entre cônjuges, a lei desobedece ao ciclo natural da separação, evitando, muitas vezes, que a reconciliação prevaleça, pois, ocorrida a ruptura da relação, aquele cônjuge que pretende deixar o imóvel deve tomar as medidas cabíveis, de modo a não dar oportunidade à aplicação da usucapião por abandono de lar.

Com a finalidade de evitar a aplicação dessa usucapião, devem os cônjuges regularizar a separação conjugal com a sua consequente partilha de bens.

Caso o rompimento do relacionamento não seja consensual, deverá aquele cônjuge que deixou o imóvel buscar medida efetiva a fim de assegurar seus direitos sobre o bem, devendo ser proposta ação de divórcio, dissolução de união estável, se for o caso, arbitramento de aluguel, concessão de usufruto ou fixação de comodato, dentro do prazo de 2 (dois) anos estabelecidos pela legislação, para que seja desnaturada a posse ininterrupta e sem oposição daquele cônjuge que permaneceu no imóvel.

Também ficará descaracterizado o abandono do imóvel, caso o ex-cônjuge ou ex-companheiro proprietário demonstre interesse pelo imóvel através da contribuição para manutenção e conservação do bem, contribuição para o recolhimento dos tributos relacionados ao imóvel, mesmo esse sendo residência apenas do outro cônjuge.

Certamente, haverá muitos enfrentamentos até que a jurisprudência se pacifique sobre os pontos controversos para a aplicação do novel instituto.

\section{REFERÊNCIAS BIBLIOGRÁFICAS}

ABULQUERQUE JÚNIOR, Roberto Paulino; GOUVEIA FILHO, Roberto P. Campos. Primeiras anotações sobre os pressupostos e a processualização da usucapião familiar. Revista de Processo. a. 36. v. 199. set./2011.

AMORIM, Ricardo Henriques Pereira. Primeiras Impressões Sobre a Usucapião Especial Urbana Familiar e suas Implicações no Direito de Família. Disponível em: 
<http://www.ibdfam.org.br/artigos/detalhe/760>. Acesso em 10 de jun. de 2013.

FONSECA, Priscila Maria Pereira Corrêa da. Considerações sobre o art.

1.240-A. Atos normativos e novidades legislativas. Revista Brasileira de Direito de Família e Sucessões. Porto Alegre: Magister; Belo Horizonte: IBDFam, a. 13, n. 23. ago. e set. 2011.

FREITAS, Douglas Phillips. Usucapião e direito de família: comentários ao artigo 1.240-A do código civil. Revista Síntese Direito de Família. v. 14. n. 71, pp. 9-15. São Paulo, abr./maio. 2012.

GUAZZELLI, Mônica. Usucapião por abandono do lar conjugal: repercussões no direito de família. Revista Brasileira de Direito de Família e Sucessões. Porto Alegre: Magister; Belo Horizonte: IBDFam, v. 28. jun./jul. 2012.

MARTINS, Fernanda da Silva. A usucapião especial urbana por abandono do lar conjugal: a volta da culpa? Artigo disponível em:

<http://www3.pucrs.br/pucrs/files/uni/poa/direito/graduacao/tcc/tcc 2/trabalhos2012_1/fernanda_martins.pdf $>$. Acesso em 19 de maio de 2013.

ORSELLI, Helena de Azeredo. Análise crítica da usucapião por abandono. Revista Síntese Direito de Família. v. 13. n. 69. pp. 129-138. dez./jan. 2012.

PALERMO, Carlos Eduardo de Castro. A nova usucapião especial por abandono de lar e a função social da propriedade. Revista Síntese Direito de Família. v. 14. n. 71, pp. 19-31, São Paulo, abr./maio. 2012.

PEREIRA, Caio Mário da Silva. Instituições de direito civil. 21. ed. Rio de Janeiro: Forense, 2012.

SILVA, Luciana Santos. Uma afronta à Carta Constitucional: usucapião pró-família. Revista Síntese Direito de Família. v. 14. n. 71, pp. 32-36. São Paulo, abr. e maio. 2012.

SIMÃO, José Fernando. Usucapião familiar: problema ou solução? Artigo disponível em: <http://www.professorsimao.com.br/artigos_simao_cf0711.html>. Acesso em 27 de maio de 2013.

TARTUCE, Flávio. A usucapião especial urbana por abandono do lar conjugal. Revista Síntese Direito de Família. v. 14. n. 71, pp. 1618. São Paulo, abr. e maio 2012. 
VILARDO. Maria Aglaé Tedesco. Usucapião especial e abandono de lar: usucapião entre ex-casal. Revista Brasileira de Direito de Família e Sucessões. Porto Alegre: Magister; Belo Horizonte: IBDFam, n. 27. abr. e maio 2012. 